\title{
Chiral histidine selection by D-ribose RNA
}

\author{
MALI ILLANGASEKARE, ${ }^{1}$ REBECCA TURK, ${ }^{1}$ G. COLIN PETERSON, ${ }^{2}$ MANUEL LLADSER, $^{2}$ and MICHAEL YARUS ${ }^{1}$ \\ ${ }^{1}$ Department of Molecular, Cellular and Developmental Biology, University of Colorado, Boulder, Colorado 80309, USA \\ ${ }^{2}$ Department of Applied Mathematics, University of Colorado, Boulder, Colorado 80309, USA
}

\begin{abstract}
The invariant choice of L-amino acids and D-ribose RNA for biological translation requires explanation. Here we study this chiral choice using mixed, equimolar D-ribose RNAs having 15, 18, 21, 27, 35, and 45 contiguous randomized nucleotides. These are used for simultaneous affinity selection of the smallest bound and eluted RNAs using equal amounts of L- and D-His immobilized on an achiral glass support, with racemic histidine elution. The experiment as a whole therefore determines whether RNA containing D-ribose binds L-histidine or D-histidine more easily (that is, by using a site that is more abundant/ requires fewer nucleotides). The most prevalent/smallest RNA sites are reproducibly and repeatedly selected and there is a four- to sixfold greater abundance of L-histidine sites. RNA's chiral D-ribose therefore yields a more frequent fit to L-histidine. Accordingly, a D-ribose RNA site for L-His is smaller by the equivalent of just over one conserved nucleotide. The most prevalent L-His site also performs better than the most frequent D-His site-but rarer D-ribose RNAs can bind D-His with excellent affinity and discrimination. The prevalent L-His site is one we have selected before under very different conditions. Thus, selection is again reproducible, as is the recurrence of cognate coding triplets in these most probable L-His sites. If our selected RNA population were equilibrated with racemic His, we calculate that L-His would participate in seven of eight His:RNA complexes, or more. Thus, if D-ribose RNA were first chosen biologically, translational L-His usage could have followed.
\end{abstract}

Keywords: stereoselection; amino acid; ribose; simultaneous successively squeezed selection; aptamer

\section{INTRODUCTION}

\section{Dual overall purpose}

Our immediate biological predecessors probably made more extensive use of an RNA-like molecule, perhaps using it as the only macromolecule for a time. This ancient congener of RNA thereby predates other modern macromolecules. One elementary prediction of these views is that RNAs must have first performed translation (so that RNA catalysts could be replaced with encoded peptide catalysts). Thus, RNA alone must be competent in a form of templated peptide synthesis (Yarus 2001).

This in turn implies that some amino acids were first admitted to coded peptide sequences via interactions with RNA. Such binding interactions are chemically plausible, and have been characterized for many genetically encoded amino acids (Yarus et al. 2009; Johnson and Wang 2010). Accordingly, universal use of $\mathrm{L}$-amino acids in proteins could reflect

Reprint requests to: Michael Yarus, Department of Molecular, Cellular and Developmental Biology, University of Colorado, Boulder, CO 80309 , USA; e-mail: yarus@stripe.colorado.edu; fax: (303) 492-7744.

Article published online ahead of print. Article and publication date are at http://www.rnajournal.org/cgi/doi/10.1261/rna.2385310. amino acid choice via chiral interactions with the D-ribose RNA backbone. (L- and D- as used here denote a resemblance to the substituents in mirror images of L- and D-glyceraldehyde, as is usual in biochemistry.) However, chiral ribose may play a greater or lesser part in the folds of amino acid binding sites, so RNA's effective chiral preference for amino acids requires experimental definition.

We have shown that histidine is among the amino acids probably admitted to the code via interactions with RNA. Selected histidine binding sites contain improbable numbers of cognate anticodons (Yarus et al. 2005, 2009). Therefore, histidine is one amino acid likely to have been introduced into translation via a direct RNA-amino acid interaction. Accordingly, in these present experiments, we compare the simplest/ most accessible RNA sites for D- and L-histidine by seeking the most abundant RNAs eluted by racemic amino acid. This account is therefore first, about chiral preference in an amino acid-RNA interaction, but second, about a method for determining which of two similar reactions is simpler for RNA, which we call simultaneous successively squeezed selection.

\section{Previous work on chiral preference}

Chiral selection of amino acids by nucleotides has been pursued in the past by measuring differential rates of aminoacylation 
of ribonucleotides by activated D- and L-amino acids. Profy and Usher used racemic DNB-alanine imidazolides to acylate poly A, I, C, and U. They found L-alanylation more rapid by almost fourfold (poly A) to about twofold (poly C) (Profy and Usher 1984). However, when the DNB protecting group was removed, more nearly emulating aa-tRNA synthesis, the stereospecificity flipped, with $\mathrm{D}$-amino acids selected by D-RNA. Another small acylation model, using acetyl-D-L valine to acylate all four $5^{\prime} \mathrm{NMP}$, gave unbiological results, suggesting consistent superiority for the D-amino acid (Wickramasinghe and Lacey 1992).

Tamura and Schimmel more recently used a macromolecular model —a 5' P-aminoacyl deoxyoligonucleotide (emulating an amino acid adenylate) at a nick in an RNA-RNA hybrid helix. Activated L-alanine was transferred across the nick to an RNA 3' adenosine $\mathrm{OH}$ at about four times the rate of D-alanine (Tamura and Schimmel 2004). This quantitative outcome depended on structure at the nick. Furthermore, in supplementary data for the hybrid helix in the same manuscript, permutation of the amino acid sidechain, phenylalanine to leucine to alanine, made little difference to the result. Thus, the sidechain is not being closely observed by the RNA-RNA hybrid experimental system. This seems difficult to reconcile with later suggestions that sidechain contacts are crucial to observed fourfold stereoselection (Tamura and Schimmel 2006). In addition, a reaction is an improbable model for coding unless it is sidechain-specific. Finally, aminoacylation across a nicked RNA-DNA hybrid helix junction seems particularly difficult to place in a translational context because evolution of sophisticated peptide catalysis and therefore translation is thought to predate DNA (Freeland et al. 1999).

Therefore, it appeared useful to ask independently if preferential chiral interaction between L-amino acids and D-ribose-RNAs exists. Binding may be an effective way to ask this question because a stably bound chiral amino acid ligand can be enveloped by the RNA (Batey et al. 2004), potentially utilizing a greater molecular contact surface to yield a more specific result.

\section{RESULTS}

\section{Description of the affinity selection}

We began with a set of selections designed to define the simplest/most abundant isolable RNA binding sites for both D-His and L-His. A successively squeezed selection (that is, with randomized RNAs of decreasing length [Lozupone et al. 2003]) defines the simplest functional RNA by determining the active RNA that occurs in the shortest randomized tract in which the selection succeeds. RNAs that vary in the length of their randomized tract over a shortened, moderate range (Coleman and Huang 2002) are mixed, handled together, and only distinguished at the end of the experiment.
Figure 1 shows how a squeezed selection can be elaborated to accurately compare the simplest sites for two functions. D-ribose RNAs (that is, normal RNAs) of different randomized tract lengths are mixed and the population is bound and eluted from an L-His-CPG-D-His column by racemic free histidine. Selection using binding and elution with L- and D-His together compares the simplest forms of RNA binding the stereoisomers in the same experiment, thereby internally controlling all aspects of the comparison. We will call this comparison of two binding reactions a simultaneous successively squeezed selection. The most abundant RNA at the end of this selection is probably the simplest one. While it is hypothetically possible that a simpler RNA (requiring looser constraints on more nucleotides) might be physically larger, such hypothetical RNA could be seen among the longer tracts included in the simultaneous selection, and has not been observed.

We used selection protocols designed to collect a broad variety of His-binding activities, including those with different $K_{\mathrm{D}}$. Equal amounts of $\mathrm{D}$ - and L-amino acids were immobilized on achiral controlled pore glass (CPG). This mixed support is exposed to $10^{14}-10^{15}$ different RNA sequences. The His-CPG column is eluted with a racemic mix of amino acid at a relatively high concentration. This displaces all histidine-binding RNA whose $K_{\mathrm{D}}$ is equal to or smaller than the eluting histidine concentration into the near-void volume. This pooled His-binding RNA population is reamplified until RNA that binds His becomes a plurality of the population (Fig. 1). Under this evenhanded selection, does RNA binding the L- or D-amino acid

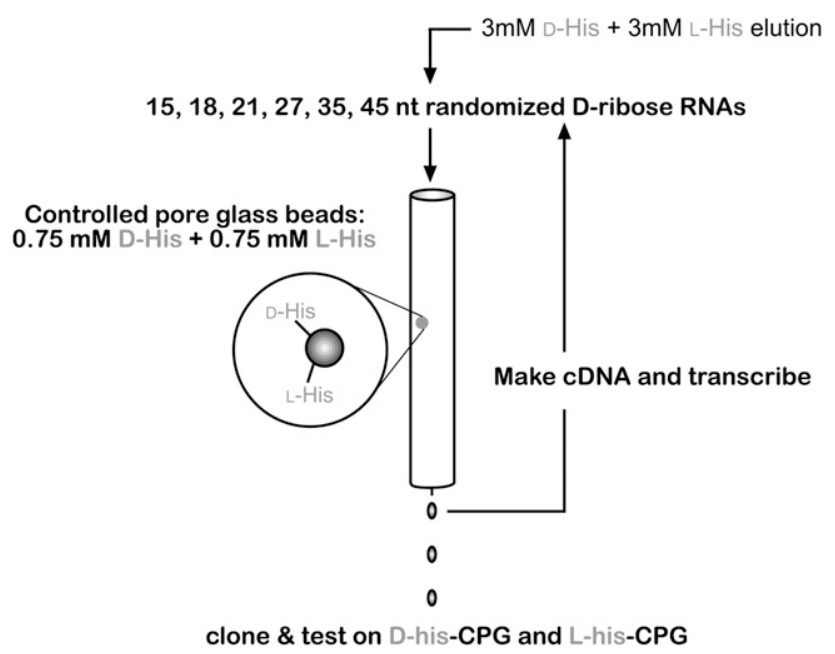

FIGURE 1. Method for the simultaneous successively squeezed selection of RNA with L-His and D-His affinity. RNAs with different randomized tracts are mixed and applied together to a column of achiral controlled pore glass $(\mathrm{CPG})$ beads bearing equal concentrations of L-His and D-His, coupled through the carbonyl to a hydrophilic arm. Concentration of column-bound histidine refers to the amount of histidine in a volume of the packed bed. The CPG columns are washed, then eluted with racemic His in solution at relatively high concentration - this procedure is designed to pool all histidine-binding RNAs in one early eluted fraction. This fraction is recycled via cRNA synthesis and transcription (see Materials and Methods) until major fractions of the RNA population are eluted by free histidine. 
arise more easily? "More easily" might mean that the D- or L-selection succeeds in an earlier selection cycle. Alternatively (and closer to what we find), D- and L-selections succeed almost simultaneously, but one kind of binding site is more abundant/smaller than the other.

\section{Design of randomized RNA}

Figure 2 shows the structure of the randomized RNA molecules for the first selection, incorporating several considerations from prior work. First, flanking constant sequences contain no histidine codons (CAY) or anticodons (RUG). This is also true in all later selections below. Because interaction between randomized and constant sequences can never be excluded, this precaution prevents induction of coding triplets, which are of interest to us, via interactions that might not be evident.

Second, interactions between the constant and selected RNA sequences (for example, Legiewicz and Yarus 2005) are suppressed by constant-constant helices that usually keep primers from pairing with selected sequences. This constant structure is shown in the lower part of Figure 2. However, this helix must not be too stable or it will force a relation between constant and randomized sequences by a more subtle route-it will depress selection of certain desired motifs by forcing selected sequences to incorporate the preexisting constant helix (Legiewicz et al. 2005). Therefore, the constant helices are destabilized by a small internal loop, with a proximal helix of only four base pairs.

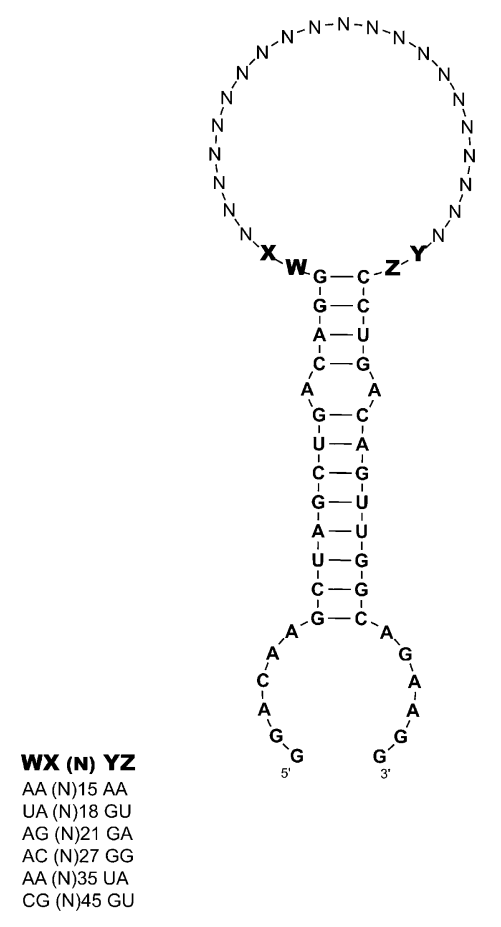

FIGURE 2. Structure of the tagged, randomized RNA population for the initial selection. The boldface shows sequence tags used to mark the two ends of the randomized tract distinctively for each tract length; $15,18,21,27,35$, or $45 \mathrm{nt}$ in different molecules. $\mathrm{N}$ implies $\sim 25 \%$ of each nucleotide.
Thirdly, there are short unpaired constant sequences between the randomized tract and the primer-complementary constant sequences - these unpaired two-nucleotide tags on each side are marked W, X, Y, and Z in Figure 2. Tags usually differ on the $5^{\prime}$ and $3^{\prime}$ and are unique for each randomized region length (Fig. 2). These tags serve multiple purposes; they are noncomplementary and were intended to further decouple preexisting constant helices from the randomized nucleotides (Legiewicz and Yarus 2005). In addition, the recovery of canonical tags argues against selection of active molecules via recombination between randomized regions of different lengths. Recombined molecules could not be simply interpreted in terms of initially supplied randomized tract lengths.

The initial randomized population contained equal numbers of RNAs containing tracts of 15, 18, 21, 27, 35, and 45 randomized nucleotides. These are mixed at the start and handled together thereafter so as to carry out unbiased selections with decreasing space for the selected motif. One obstacle to this goal is that larger molecules might have a replication disadvantage, as they did in selections with randomized tracts up to 140 nucleotides (nt) long (Coleman and Huang 2002). However, with the present shorter randomized tracts, this appears not to be troublesome (below).

\section{Progress of the first selection}

Equal numbers of transcript RNA molecules, as judged from absorbance, were mixed to yield approximately five copies of $3 \times 10^{14}$ independent sequences for each of the six tract sizes. This population should include all possible ribonucleotide sequences of the 21,18 , and 15 nt lengths, but will be more sparsely sampled at 27,35 , and 45 consecutive randomized nucleotides.

Figure 3A shows the distribution of RNA lengths before each selection, cycles 2-6. Allowing for differential labeling due to size, all molecules are approximately equimolar in the early cycles. Further, all RNA lengths remain observable to the point of cloning after cycle 6, though the intensities of the different size classes change (to favor active 21-nt tracts) when selection becomes a dominant influence on the population in the last two cycles.

The blindly sampled and sequenced molecules of the cloned population (Fig. 3A, numbers on the right) agree very well with the apparent abundances from cycle 6 in the gel autoradiogram, with $21 \mathrm{nt}$ randomized most prevalent, smaller molecules rare, and evident but less abundant larger RNAs. Therefore, cloned populations accurately sample selected molecules.

In the first three cycles, before selection begins to change the length distribution, RNAs all are replicated equally and the initial size distribution is approximately maintained. Therefore, among these molecules, replication disadvantage for the larger RNAs does not dominate the fates of the different size classes (Coleman and Huang 2002). In fact, in other selections performed alongside these and using similar randomized RNAs (but not shown), the largest molecules 
A

\begin{tabular}{|c|c|c|c|c|c|c|}
\hline & \multicolumn{5}{|c|}{$\begin{array}{l}\text { RNA input for affinity column } \\
\text { Selection cycle number }\end{array}$} & \multirow[t]{2}{*}{$\begin{array}{l}\text { Number of } \\
\text { sequences cloned }\end{array}$} \\
\hline & 2 & 3 & 4 & 5 & 6 & \\
\hline $45 \mathrm{~N}$ & is & 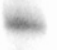 & $i$ & $=$ & $=$ & 4 \\
\hline $35 \mathrm{~N}$ & $\omega$ & $=$ & - & - & - & 7 \\
\hline $27 \mathrm{~N}$ & 6 & $=$ & $=$ & $=$ & - & 24 \\
\hline $\begin{array}{l}21 \mathrm{~N} \\
18 \mathrm{~N} \\
15 \mathrm{~N}\end{array}$ & 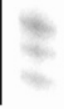 & $=$ & $=$ & $=$ & $\sigma$ & $\begin{array}{r}49 \\
1 \\
3\end{array}$ \\
\hline
\end{tabular}
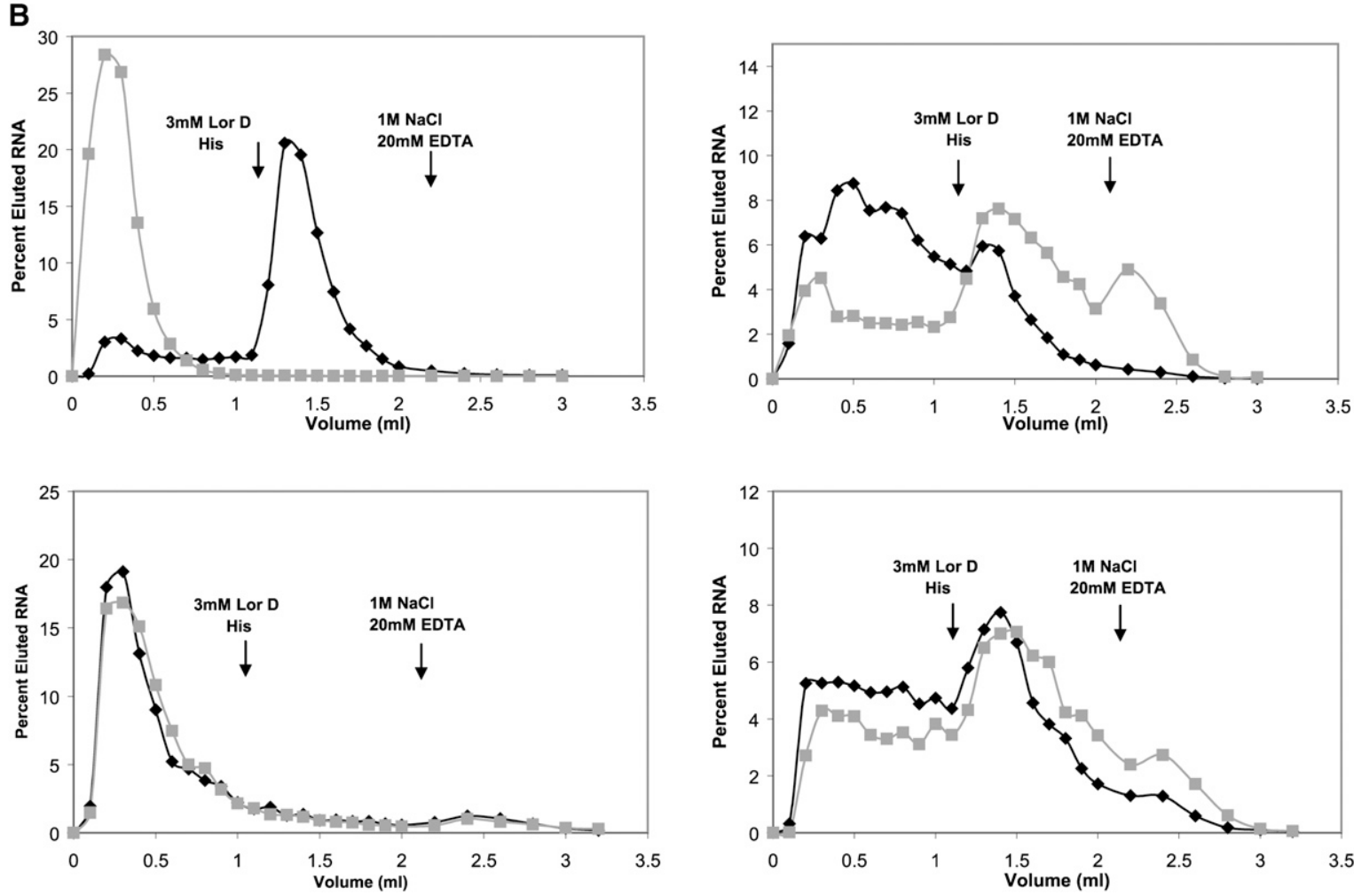

FIGURE 3. (A) Radioautogram to summarize the progress of selection by gel electrophoresis. Generally $\left[{ }^{32} \mathrm{P}\right] \mathrm{G}-\mathrm{labeled}$ RNA samples taken from RNA applied to the CPG-D/L-His column were fractionated on an $8 \%$ denaturing acrylamide gel, and scanned in a phosphorimager. Numbers at the left are the size of the randomized tract, and on the right, the numbers of clones from that size tract sequenced after cycle 6 . $(B)$ Classification of RNA transcripts by affinity chromatography, using individual RNAs as examples. Dark lines show $3 \mathrm{mM}$ L-His elution from CPG-L-His and gray lines show 3 mM D-His elution from CPG-D-His. (Top left panel) Predominant L-affinity (RNA 67), (bottom left panel) no observable His affinity (RNA 69), (top right panel) predominant D-affinity (RNA 23), and (bottom right panel) both D- and L-affinity (RNA 80).

(45 nt randomized) were most prevalent at selection's end (M Illangasekare and M Yarus, unpubl.). Therefore, molecular abundances among selected molecules having 15-45 randomized nucleotides can be interpreted without according differential replication a dominant role.

\section{Classification of D- and L-His sites}

We distinguish L-specific and D-specific aptamers, as well as a minority that do not discriminate, by chromatography on L-His-CPG and D-His-CPG. Elution profiles in Figure 3B illustrate RNA classification.
The most prevalent L-His binding RNA is specifically eluted by L-His from L-His-CPG (upper left; dark line), and shows no obvious response to D-His and D-His-CPG (upper left, gray line; measured $K_{\mathrm{D}}$ 's are in Table 4 below). The most prevalent $\mathrm{D}$-His-specific RNA prefers $\mathrm{D}$-His (upper right; gray), but has an observable response to $3 \mathrm{mM}$ L-His on L-His-CPG (dark line). The major D-His-specific RNA thus makes a smaller distinction between $\mathrm{L}$ - and $\mathrm{D}$-His than does the smallest L-specific RNA. Indeed, the smallest D-His site bears some resemblance to the rare isolate we term nonspecific (lower right), that binds, but makes no apparent distinction between L-His and D-His. We make these 
differences quantitative by measuring and presenting $K_{\mathrm{D}}$ in Table 4 below, and also take them into account in evaluating the selection outcome. Finally, an RNA with no significant Dor L- histidine affinity is profiled at the lower left.

Table 1 surveys the results in terms of these specificities. Selected RNAs usually had the expected initial tags, suggesting that functional sequences rarely arose from recombination between the initial molecules. The premise of the squeezed selection is also met, in that selection is successful until the randomized region becomes smaller than $21 \mathrm{nt}$ long, and then both 15- and 18-nt selections fail, as was apparent in Figure 3A. L-specific sequences are $92 \%$ the major L-specific motif described later, and D-specific sequences are $91 \%$ the other major motif, so one type of binding site sequence is dominant just before randomized tracts become too short to accommodate any active RNA structure. The 13 sequences that have no observable affinity for the column (Table 1) (15\%) are of a type always observed, which do not meet the selection criterion but survive by an unknown route. For example, such parasitic sequences might have a cryptic strong affinity for a functional sequence (Vlassov et al. 2001).

One 18-nt isolate in Table 1 (RNA 99) (full sequence set in Supplemental Table 1) needs further comment. It appears that RNA 99 contains 15 nt between flanking AA tags. This sequence strongly suggests that RNA 99 is a derivative of an AA15NAA parent that provided most of the conserved nucleotides of the major L-His motif with the aid of a CA insertion just outside its three-prime tag; ...caggA $\underline{\underline{A G U}}$

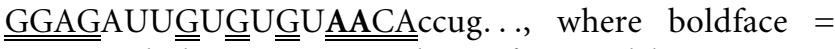
TAG, underline $=$ conserved motif nt, and lower case $=$ flanking constant sequence. There appears no comparably parsimonious way to explain its origin in another parental sequence. Thus, RNA 99 actually has $21 \mathrm{nt}$ between flanking primer complements-its low frequency and size represent an improbable route to the dominant L-His site, and not a novel motif. All active binding sites therefore originated in 21-nt or larger tracts.

All possible 21-mer sequences were probably tested in this experimental design. About 70 copies of every possible 21-mer were present initially. Because both D- and L-His specificities appear at $21 \mathrm{nt}$, it is likely not only that these are

TABLE 1. Outcome of the initial tagged selection, shown in Figure 3

\begin{tabular}{lrrrrrrrrrr}
\hline & \multicolumn{7}{c}{ Random length $(\mathrm{N})$} & & & \\
\cline { 2 - 7 } & 15 & 18 & 21 & 27 & 35 & 45 & Total & \%Total & \%Major motif \\
\hline D-Specific RNA & 0 & 0 & 34 & 0 & 1 & 0 & 35 & 40 & 91 \\
L-Specific RNA & 0 & 1 & 9 & 21 & 5 & 2 & 38 & 43 & 92 \\
L\&D-Nonspecific RNA & 0 & 0 & 0 & 1 & 0 & 1 & 2 & 2 & \\
Nonbinding RNA & 3 & 0 & 6 & 2 & 1 & 1 & 13 & 15 & \\
Total & 3 & 1 & 49 & 24 & 7 & 4 & 88 & & \\
\hline
\end{tabular}

a"Major motif" implies RNA 23-like sequence for D-specific RNAs and RNA 67-like sequence for L-specific RNAs (such sequences can be compared in Table 2, Fig. 5, and supplementary sequence tables). the simplest sequences isolable in this experiment, but that no other oligoribonucleotides with comparable activity under our conditions exist. There will be further supporting evidence for this conclusion below.

\section{Rough summary of first selection}

Accordingly, the first selection suggests that the complexities of a D-His- and an L-His-specific RNA fold are roughly similar. First, both D- and L- specificities are observed in the 21-mer tract, and neither activity appears among bona fide 15- or 18 -mers. Second, specificities are about equally easily isolated overall—there are $38 / 88=43 \%$ L-specific motifs and $40 \%$ D-specific motifs in the cloned pools. These abundances are indistinguishable. Therefore L- and D-amino acid specificities are about equally prevalent, with neither predominant in the selection as a whole. Nevertheless, closer examination below suggests that the outcome was more biased than is evident from this overall pool census.

\section{Defined motifs}

The structures of the most prevalent D- and L-His motifs were determined by doping and reselection on representative sequences. To derive the conserved structure most consistent with the substitutions in aligned sequences, and to determine the latitude for substitution of nucleotides, we mutagenized and reselected the three detected motifs. Accordingly, nucleotides at and between the arrows (35 nt) (Fig. 4) were substituted with $70 \%$ original nucleotide and $10 \%$ of each mutant nucleotide and this population was subjected to simultaneous D-His and L-His selection, just as in their original isolation. Figure 4 shows the calculated secondary structure of the leading L-specific (prototype RNA 67) and major and minor D-specific RNAs (prototypes RNA 23 and $62 \mathrm{~b}$ ) based on aligned sequences, along with some performance data.

Reselection of the doped sequences (with new primers) yields overwhelmingly (100\%) the three original D-histidine and L-histidine motifs, confirming that no simpler RNA structure with binding activity is nearby in sequence space (Supplemental Table 2). Table 2 shows the composition of 46 aligned sequences from the major reselected D-specific motif, 60 sequences for the minor D-specific motif, and 42 sequences from the reselected L-specific motif.

Most importantly, these data suggest that the initial selection was not a tie. Though the D-His and L-His motifs appeared to show similar abundances in the initial tagged selection (Table 1), the major L-histidine-specific motif is instead probably the more frequent. The key to this question is in Figure 4, where 
the original 2-nt tags are in boldface. By accident, three of four tag nucleotides supplied were also used at conserved positions by the major D-His motif and two of the four are used by the minor D-His motif, whereas they are less relevant to the L-motif. So, because we supplied fixed tag nucleotides (under other rationales explained above), we gave the D-motifs an arbitrary statistical advantage, leading to an apparent tie between D- and L-His RNA sites.

\section{Selection without bias from sequence tags}

To determine whether this interpretation was correct, we repeated the selection without flanking tags. Figure 5 shows the design of the pool for a simultaneous successively squeezed selection using mixed equimolar evenly randomized regions 28 , 25 , and 22 nucleotides long (that is, just above the length where the selection failed before). These short randomized regions are surrounded by new primers that again meet our sequence and structure constraints (discussed above) but without flanking 2-nt tags.

The results of the untagged selections are shown in Table 3 (sequences are in Supplemental Table 3). Using new randomized pools with new fixed sequences, the previous major $\mathrm{D}$-His and L-His motifs are again predominant (97\%) among selected sequences. This result re-re-confirms their status as the most prevalent RNA sequences with reproducible histidine affinity in randomized pools, independent of constant sequences, which were changed again for the untagged reselection. Table 3 also shows that at all these shortened randomized lengths, the major L-motif predominates, by 3.3-fold (28 nt), 7.7-fold (25 nt), and indefinitely (22 nt, the one D-specific motif was not the major one). This is consistent with our expectation; it independently confirms that L-histidine affinity is simpler/more frequent in three new selections, and thus that D-His specificity was artificially elevated by incorporation of tag nucleotides.

The minor D-specific motif, RNA 62b, does not reappear in the three untagged selections. This multiply confirms that it is rare/improbable. In fact, the RNA62blike site occurred in only one of seven useful selections, where it was favored by tag bias (below).

\section{We have seen the L-His aptamer before}

Table 2 compares L-histidine binding motifs to show an additional quality of these results; we have previously isolated and published the prevalent L-specific motif (Majerfeld et al. 2005). The previous selection for an $\mathrm{L}-\mathrm{His}$ binding site was performed by a different experimentalist, on a very different chromatographic support (Sepharose rather than glass), with different fixed sequences, under different buffer conditions. In these present experiments we have reisolated this major L-histidine site in the context of four different fixed sequences (due to tags), and three different primers in eight selections. Thus, the successively squeezed selection robustly detects the earlier dominant L-His site, in support of the idea that it isolates the simplest RNA site with the selected activity.

As a particular example of reproducibility, partially conserved histidine anticodons GUG and highly conserved AUG reappear (e.g., Table 2) among the prevalent binding site nucleotides in these experiments, confirming the previously noted link between histidine binding sites and

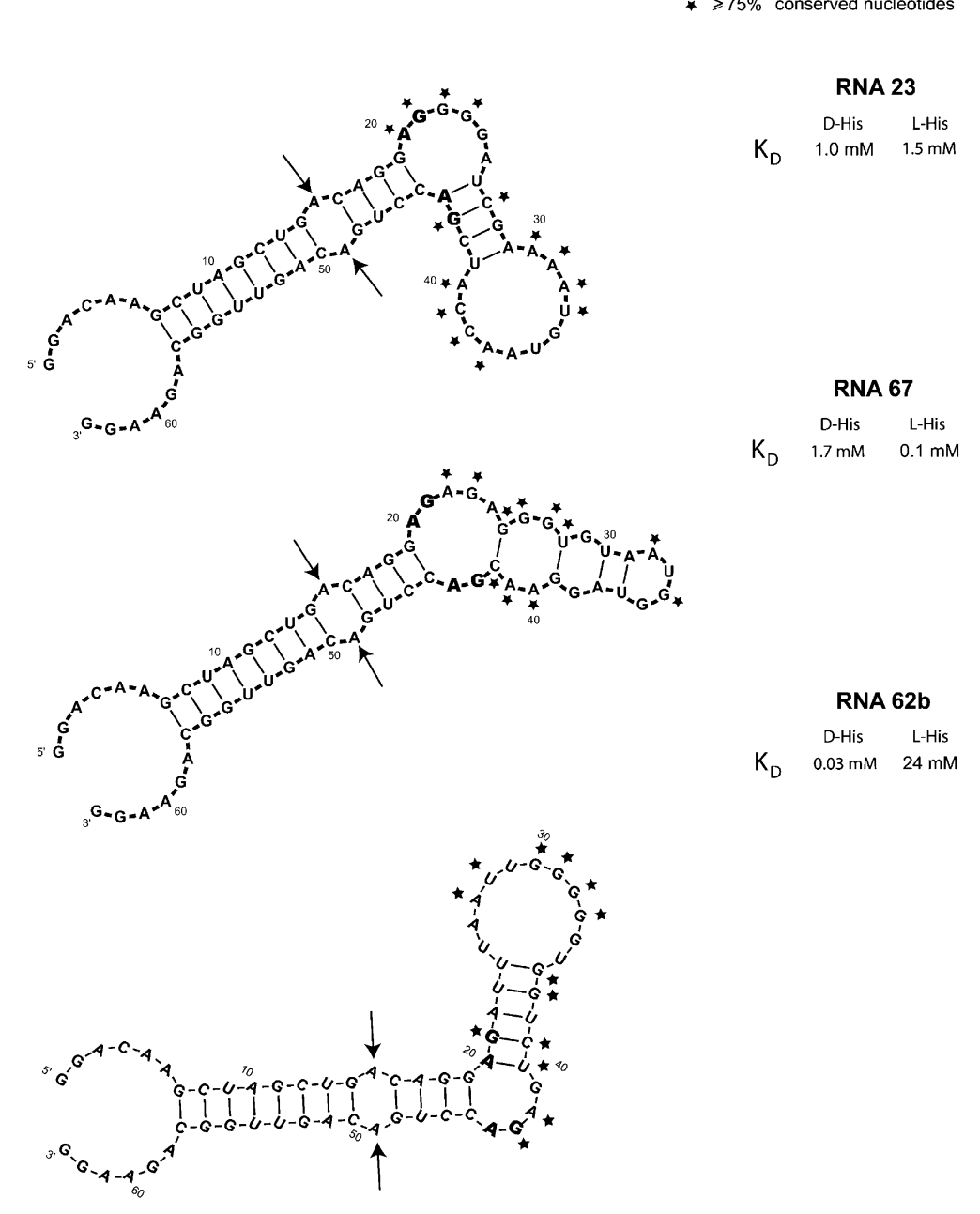

FIGURE 4. An example of the major D-Histidine binding sequence (RNA 23), the minor D-His binding sequence (RNA 62b) and an example of the major L-His binding sequence (RNA 67) with measured $K_{\mathrm{D}}$ for L-His and D-His. Arrows indicate the first and last nucleotide of the tract doped for reselection. Starred nucleotides are conserved ( $\geq 75 \%$ ) (Table 2 ) and the boldface marks the initial sequence tags for the RNA shown. 


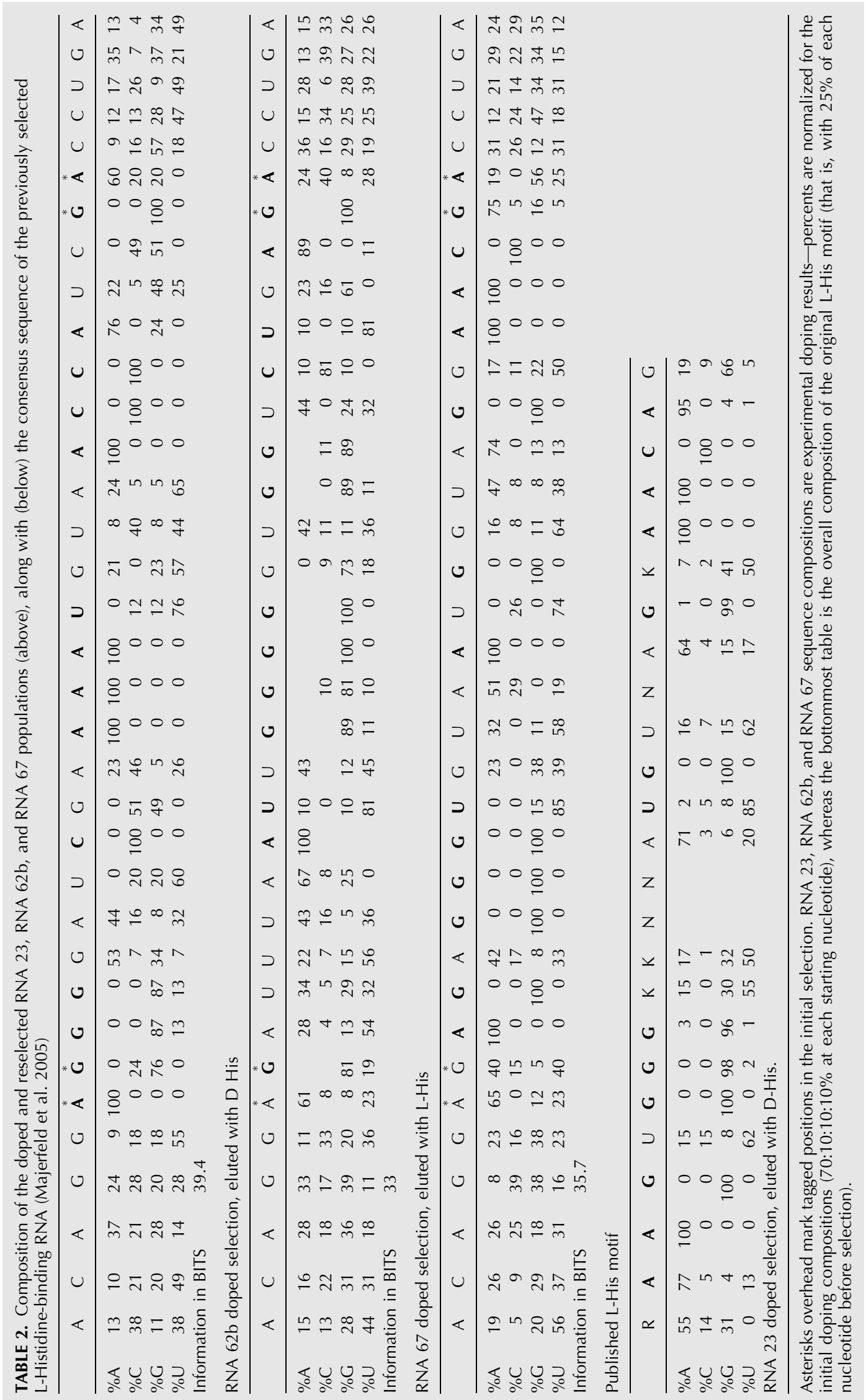




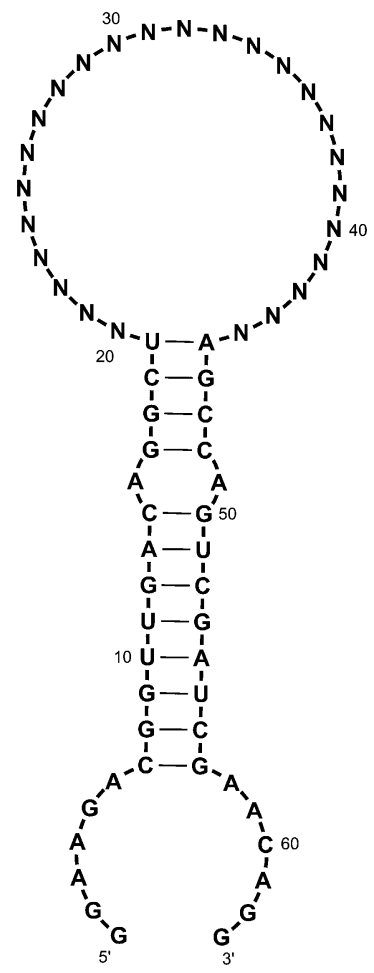

FIGURE 5. Structure of the RNA population for the untagged reselection. $\mathrm{N}=$ randomized position implies $\sim 25 \%$ of each nucleotide. N comprised 22, 25, and $28 \mathrm{nt}$ in the mixed populations of this simultaneous squeezed selection for L-His and D-His affinity.

histidine coding triplets (Majerfeld et al. 2005; Yarus et al. 2005, 2009).

\section{Role of the sidechain}

Amino acid binding sites selected by these techniques usually distinguish between differing sidechains (Yarus et al. 2005, 2009). This is relevant to these experiments because sites employed in coding must distinguish amino acids.

Therefore, we have measured the dissociation constants for chemically varied amino acids using isocratic affinity elution (Ciesiolka et al. 1996) at different eluant concentrations (Fig. 6). Isocratic affinity chromatography is an equilibrium method that gives binding constants indistinguishable from those measured by equilibrium dialysis or equilibrium ultrafiltration (Majerfeld and Yarus 2005) or ligand protection from chemical modification (Illangasekare and Yarus 2002; Majerfeld et al. 2005). Crucial $K_{\mathrm{D}}$ 's, measured at $\mathrm{pH} 7$, are collected in Table 4 . Apparent $K_{\mathrm{D}}$ can be $\mathrm{pH}$-dependent; it is the protonated histidine sidechain that is bound for the prevalent L-histidine site (Majerfeld et al. 2005).
The overall conclusion is that sidechain selectivity is observed, though not equivalently for all sites. The prevalent $\mathrm{D}$-His site is only 1.5 -fold selective $(\Delta \Delta G=0.2 \mathrm{kcal} / \mathrm{mol})$ against its noncognate stereoisomer, whereas the $\mathrm{L}-\mathrm{His}$ site is 17 -fold stereoselective $(\Delta \Delta G=1.7 \mathrm{kcal} / \mathrm{mol})$. In fact, the simplest D-His site is only slightly more discriminating than sequences we have classified as nonspecific. However, a simple D-ribose RNA site can strongly favor D-His; the rarely appearing RNA $62 \mathrm{~b}$ is almost 1000 -fold selective for D-His $(\Delta \Delta G=4.1 \mathrm{kcal} / \mathrm{mol})$.

These data support and quantify the difference between stereoisomers observed in the classification chromatography in Figure 3B. Both the most prevalent L-specific and D-specific sites show a moderate affinity for other basic amino acids that is not extended to neutral sidechains, but the L-specific site discriminates noncognate sidechains by $27-\geq 800$-fold $(\Delta \Delta G=2-\geq 4 \mathrm{kcal} / \mathrm{mol}$ ), whereas the $\mathrm{D}$-specific site discriminates by $3.9-\geq 80$-fold $(\Delta \Delta G=$ $0.8-\geq 2.6 \mathrm{kcal} / \mathrm{mol}$ ). The prevalent D-His D-RNA aptamer also binds its primary ligand 10-fold less well than the L-motif $(\Delta \Delta G=1.4 \mathrm{kcal} / \mathrm{mol})$, though rare $\mathrm{D}$-His site is threefold stronger than RNA 67 with L-His.

Therefore all prevalent aptamers observe the chemical character of the sidechain, and both infrequent D- and frequent L-His sites can be stereo- and sidechain selective. This likely means that both kinds of sites have either double-ended polar profiles or affinity for both $\alpha$-carbon and sidechain features (Yarus et al. 2009).

\section{DISCUSSION}

\section{The simultaneous selection protocol}

Here we have elaborated the successively squeezed selection (Lozupone et al. 2003), which seeks the smallest active RNA, into the simultaneous successively squeezed selection, which compares the smallest RNA motifs having two activities selected simultaneously, using a single RNA solution (Fig. 1). The protocol compares the most readily arising RNAs that can potentially perform any simultaneously selectable functions, as for D-His and L-His affinity here. It is internally controlled because all randomized tract lengths are selected
TABLE 3. Outcome of the reselection without tag sequences

\begin{tabular}{|c|c|c|c|c|c|c|}
\hline & \multicolumn{3}{|c|}{ Random length $(\mathrm{N})$} & \multirow[b]{2}{*}{ Total } & \multirow[b]{2}{*}{$\%$ Total } & \multirow[b]{2}{*}{$\%$ Major motif } \\
\hline & 22 & 25 & 28 & & & \\
\hline D-Specific RNA & 1 & 4 & 7 & 12 & 18 & 83 \\
\hline L-Specific RNA & 4 & 23 & 23 & 50 & 73 & 98 \\
\hline $\begin{array}{l}\text { L\&D-Nonspecific } \\
\text { RNA }\end{array}$ & 2 & 0 & 0 & 2 & 3 & \\
\hline Nonbinding RNA & 3 & 1 & 0 & 4 & 6 & \\
\hline Total & 10 & 28 & 30 & 68 & & \\
\hline
\end{tabular}

See Table 1 for terminology. 

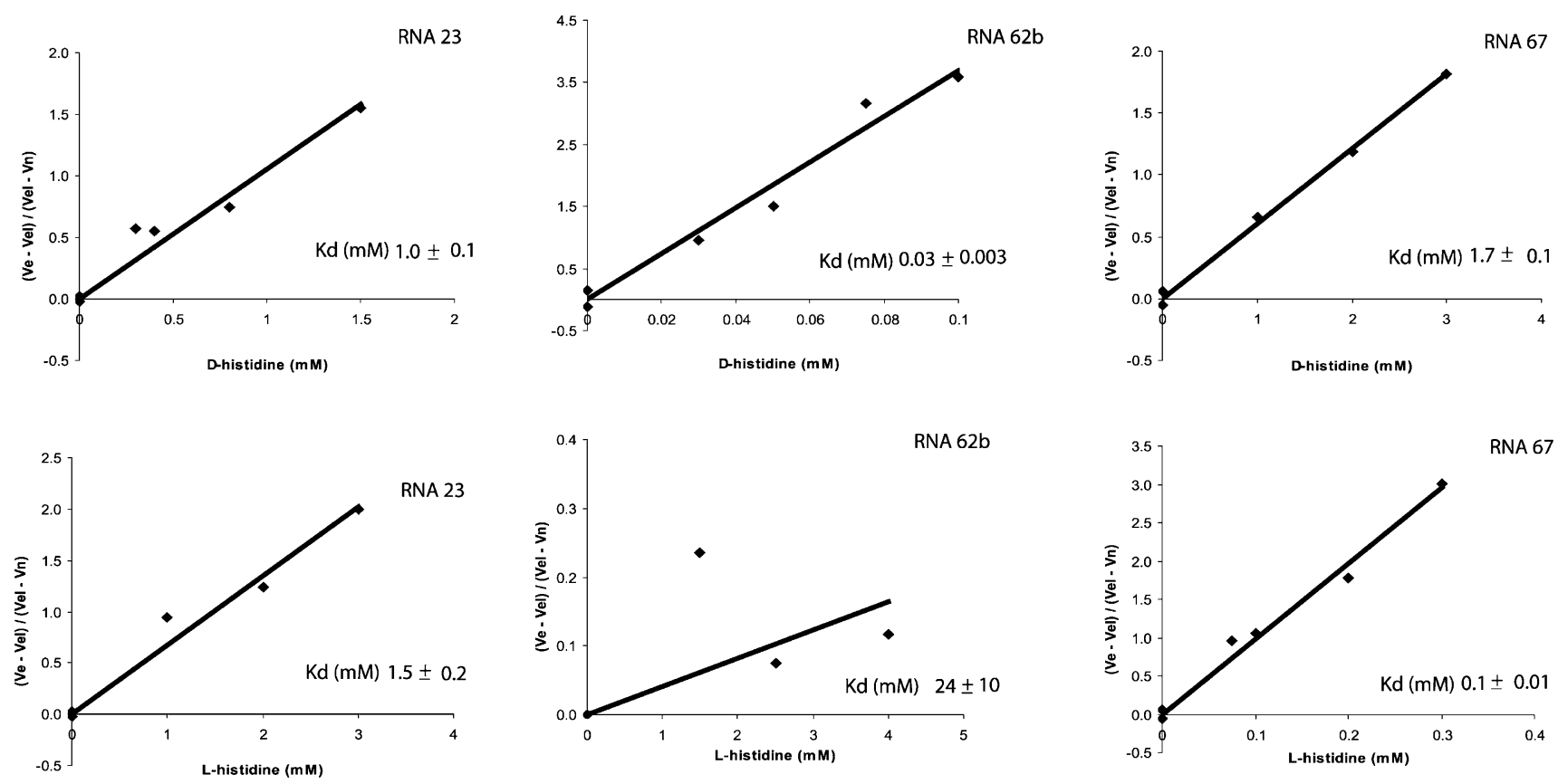

FIGURE 6. Plots of elution by ligand in double affinity chromatography experiments on typical examples of each class of selected His binding sites (see Materials and Methods). The slope of the plot versus His concentration is $K_{\mathrm{D}}{ }^{-1}$; these values are collected in Table 4 . Each point is derived by combining data from an affinity elution without histidine, and an isocratic histidine affinity elution (see Materials and Methods)

under conditions that are necessarily the same. Preservation of tags and use of different constant sequences shows that reproducible outcomes are independent events, not attributable to, e.g., contamination. The reproducible reisolation of the same abundant sites, even when conditions and sequence context are changed, is most easily explained by the hypothesis that the repeated isolate presents the simplest and therefore the most abundant active structure in multiple independent populations of randomized sequences.

In this connection, we emphasize that the selection must accept RNAs with different levels of activity, and that confining the randomized tracts to a range of short lengths avoids the otherwise overwhelming replication disadvantage observed when selection is performed with longer randomized tracts (Coleman and Huang 2002, 2005). Concentration on short sequences also potentially enables testing of all possible sequences. When active sequences (as here) recur among fully tested RNA tract sizes, one has evidence that no other short active RNAs exist.

\section{RNA chemistry and evolutionary questions}

The chemistry of modern RNA is surprisingly relevant to evolutionary questions. The core octamer of the ribosomal peptidyl transferase is also the favored binding site sequence adjacent to a transition state analog for peptide bond formation (Yarus and Welch 2000). This implies that this core peptidyl transferase sequence came from selection on a molecule very like modern RNA (because RNA activities are usually disrupted by minor modification of their nucleotides
[Paul et al. 2006]). Similarly, in all four cases so far examined, successively squeezed selection shows that the simplest binding sites for Ile (Lozupone et al. 2003), Trp (Majerfeld and Yarus 2005), His (Majerfeld et al. 2005), and Arg (Janas et al. 2010) contain essential cognate coding triplets. Thus, the finding (Yarus et al. 2005, 2009; Johnson and Wang 2010) that codons and anticodons occur broadly in modern RNAamino acid interactions strongly suggests that biological

TABLE 4. $K_{\mathrm{D}}$ of the major L- and D-histidine-specific isolates for varied amino acids, derived from dual-column isocratic affinity elution (Ciesiolka et al. 1996)

\begin{tabular}{lccc}
\hline & \multicolumn{3}{c}{$K_{\mathrm{D}}(\mathrm{mM})$} \\
\cline { 2 - 4 } Amino & & & \\
acid & D-His RNA 23 & L-His RNA 67 & D-His RNA 62b \\
\hline L-His & $1.5 \pm 0.2$ & $0.1 \pm 0.01$ & $24 \pm 10$ \\
D-His & $1.0 \pm 0.1$ & $1.7 \pm 0.1$ & $0.03 \pm 0.003$ \\
L-Arg & 4.7 & 4.9 & 4.3 \\
D-Arg & 3.9 & 2.7 & 3.8 \\
L-Lys & 10 & 11 & 8 \\
D-Lys & $\geq 80$ & 35 & $\geq 80$ \\
L-Val & $\geq 80$ & $\geq 80$ & $\geq 80$ \\
D-Val & $\geq 80$ & $\geq 80$ & 66 \\
L-Gln & $\geq 80$ & $\geq 80$ & 66 \\
\hline
\end{tabular}

Some values are quoted \pm experimental standard errors, derived from the standard error of fitted slopes (Fig. 6). Each point comes from a column elution without ligand, compared to an isocratic elution with amino acid ligand. $K_{\mathrm{D}} \geq 80 \mathrm{mM}$ indicates a lower limit based on the absence of significant mobility change in the presence of $3 \mathrm{mM}$ eluant. 
RNAs have been chemically similar since the appearance of the genetic code.

Evolution in the RNA world arguably rested on the emergence of new gene functions from populations of generally functionless RNAs of arbitrary sequence. Such a process has predictable quantitative properties; sites of greater complexity require selection from more starting sequences (Knight et al. 2005). This is a fundamental consideration because it may be that higher performance may require more complex RNA structures (Carothers et al. 2004). It seems even clearer that RNA reactions posing different levels of difficulty will require RNAs of different sizes (Schneider et al. 1986).

Here we exemplify this reasoning by asking if it is more probable that an L-amino acid was bound by D-ribose RNA, thereby triggering the L-amino acid preference of modern translation. Clearly the RNAs selected by present techniques have covalently linked fixed sequences required for amplification, as well as the nucleotides that tie these fixed sequences to the active site. This implies that our selected oligomers are not literally the simplest possible oligoribonucleotides that have their active site activities, absent the need for cDNA synthesis and PCR amplification. Because attached fixed sequences were varied in each of these selections, their details are not crucial for the outcome. However, the work of (Anderson and Mecozzi 2005a,b) has indeed shown that aptamers derived from selection amplification can be shrunk to a considerably smaller active site, guided by molecular dynamics and structure modeling. Two examples are that a derived 13-mer binds theophylline (Anderson and Mecozzi 2005b) and a truncated 14-mer binds flavin nucleotide (Anderson and Mecozzi 2005a). However, the smallest RNA with attached fixed sequences is still the RNA with the smallest active site, so the logic of these present experiments is unaltered.

\section{Reproducible prevalence of His sites}

The squeezed selection method reproducibly selects particular sequences in shortened random regions. The multiple parallel selections performed in this simultaneous squeezed selection afford many comparisons between apparently independent selections. It is striking that the major His sites reappear in independent trials, with and without tags, and in many fixed sequence contexts, as well as in independent experiments as for L-His (Majerfeld et al. 2005). In these present experiments $\mathrm{D}$ - and L-His have been compared eight times (counting separate randomized lengths as selections) with the same motifs as the most likely outcomes. Parallel selections using separated L-His-CPG and D-His-CPG also isolated these same major motifs ( $M$ Illangasekare and $\mathrm{M}$ Yarus, unpubl.). Thus selection-amplification can give very varied results when performed in an open-ended way, but gives very reproducible results when the smallest motif is sought (Lehman 2004).

A major implication is the repeated, if moderate, ease of L-His binding to the major selectable D-ribose RNA.
"Moderate" means that six independent selection experiments reproducibly suggest a somewhat simpler structure for the untagged L-His site (Fig. 4; Table 3) under conditions designed to give $\mathrm{D}$-His and L-His specificity a rigorously equal chance. Given that specifying one conserved nucleotide reduces abundance by fourfold (Yarus and Knight 2004), we can summarize by saying that, in view of the fourfold greater abundance of L-His sites in Table 3, L-His sites require about one less nucleotide than D-His sites in D-ribose RNA.

\section{Analysis of the total selected population, instead of major isolates only}

However, we can analyze the results (Tables 1,3) more quantitatively. Define the probability that D-ribose RNA binds to D-histidine to be $(1 / 2+d)$; $d$ is the binding preference bias. First, we check whether individual selections show unique biases. Then, we estimate overall bias and test whether it differs from zero (Peterson 2010).

\section{Pooling the less biased, untagged reselection data}

We first test binding preferences for the less biased experimental design of untagged reselection (Table 3, first and second rows). Using the Pearson $\chi^{2}$ test with 2 degrees of freedom (Devore 2008), the test statistic evaluates to 0.6624 . The associated $P$-value is 0.7181 . Thus, tract lengths (viewed as different selections) do not affect the binding preference bias and the untagged selection data can be pooled. To test whether the bias is zero, we use two-tailed probabilities calculated from the Binomial distribution with 62 samples and success probability $1 / 2$, that is, with $d=0$. The $P$-value associated with $12 \mathrm{D}$-specific RNAs is $\sim 1.214 \times 10^{-5}$. Thus, there exists strong evidence that bias is nonzero. The estimate for the true bias $(d)$ of the untagged reselection (Table 3 ) is 0.3065 , favoring L-His; that is, $0.8065 \mathrm{~L}-\mathrm{His}, 0.1935 \mathrm{D}$-His RNAs.

Using the Normal approximation to the Binomial distribution, the Agresti-Coull interval (Brown et al. 2001) for the true bias $(d)$ is in the interval $[-0.3872,-0.1899]$, with a confidence of $94 \%$ or higher (see Supplemental Fig. 1). Using the alternative Clopper-Pearson interval (Brown et al. 2001), true $d$ is in the interval $[-0.3958,-0.1863]$ with at least $95 \%$ confidence.

\section{Pooling tagged and untagged sequence data}

We can also ask whether individual selections differ in the initial tagged selection (Table 1, first and second rows). Using the Pearson $\chi^{2}$ test with 4 degrees of freedom, the test statistic is 41.1478 , and associated $P$-value is $2.5 \times 10^{-8}$, indicating that the selection surely has an effect on the binding preference.

In Table 1, D-ribose RNA uniquely preferred D-histidine when the tract length was 21 . Probably this is the effect of tag bias noted above, favoring D-His sites when the advantageous 
tags are forced into closest proximity to the binding site. Removing that unique data set and using the Pearson $\chi^{2}$ test with 3 degrees of freedom, the test statistic now evaluates to 4.1379. The associated $P$-value is 0.2470 . Therefore, the rest of the tagged selection data comes from similar populations and can be pooled.

Comparing tagged selection data for tract length 21 with untagged reselection data for pooling, using Fisher's Exact test (Devore 2008), the test $P$-value is $1.754 \times 10^{-9}$, meaning that we reject the hypothesis that these data sets are similar in distribution. Comparing the rest of the tagged selection data with the untagged reselection data, the $P$-value evaluates to 0.054 , just short of significance at $5 \%$. Thus, the untagged reselection data are distributed somewhat similarly to the tagged selection data, except when $21 \mathrm{nt}$ randomized regions were adjacent to tags. Selection among these shortest molecules was probably biased by incorporation of adjacent tags (Fig. 4).

So pooling all consistent selections, the $P$-value associated with obtaining $13 \mathrm{D}$-His sites in 92 samples when the bias is assumed to be zero is $1.073 \times 10^{-12}$. Overwhelming statistical evidence therefore exists that D-ribose RNA stereoselection is nonzero. Estimated bias is $d=-0.3587$ for this largest pooled data set, again indicating that D-ribose RNA prefers binding L-histidine. Using an Agresti-Coull interval, the true proportion bias exists in the interval $[-0.4169$, -0.2727 ] with a $94 \%$ or higher confidence (see Supplemental Fig. 2). Using a Clopper-Pearson interval, the true bias is in the interval $[-0.4226,-0.2705]$ with at least $95 \%$ confidence. This bias measurement, based on six independent selections and the maximal amount of self-consistent data, is the one used below and in the abstract. Thus, D-ribose RNA more readily folds to bind L-histidine. The difference in abundance is L-His sites 0.86 , D-His sites 0.14 . This is sixfold, again indicating a difference of slightly more than one conserved nucleotide among the populations of L-His and D-His sites.

\section{L-His is preferred overall}

In fact, L-His preference is observable even if all tagged and untagged data are taken together without experimental or statistical discrimination. The probability associated with obtaining $47 \mathrm{D}$-His sites in 135 samples (when the bias is assumed to be zero) is $5.27 \times 10^{-4}$. Furthermore, estimated $d$ is -0.1518 and true $d$ is in $[-0.2317,-0.0651]$ with $\geq 95 \%$ confidence. Nevertheless, the best estimate of the bias remains that from data pooled across all similar experiments (just above).

\section{Combining prevalence and binding performance to reach a conclusion}

The best guide for evolutionary discussion may come from combining experimental abundance with experimental per- formance data. If we model the RNA world as a solution containing randomized D-ribose RNAs, in the presence of racemic histidine, then the $2 i$ equilibria between amino acids and $i$ His-binding RNAs can be written:

$$
\begin{gathered}
R_{i} L=R_{i} L / K_{i}^{L} \text { and } R_{i} D=R_{i} D / K_{i}^{D} \\
\frac{R_{i} L}{R_{i} D}=\frac{K_{i}^{D}}{K_{i}^{L}} \\
\frac{\sum_{i} R_{i} L}{\sum_{i} R_{i} D}=\frac{\sum_{i} K_{i}^{D} R_{i} L /\left[K_{i}^{D} K_{i}^{L}+\left(K_{i}^{L}+K_{i}^{D}\right) L\right]}{\sum_{i} K_{i}^{L} R_{i} D /\left[K_{i}^{D} K_{i}^{L}+\left(K_{i}^{L}+K_{i}^{D}\right) D\right]}
\end{gathered}
$$

where the upper equations define binding reactions between $i$ individual histidine-binding RNAs and D and $\mathrm{L}$ amino acids, with individual dissociation constants $K_{i}^{D}$ and $K_{i}^{L}$. Each type of RNA occurs in complex with racemic $\mathrm{D}$ - and L-amino acids in a constant ratio independent of amino acid concentration, defined in the middle line. The overall population ratio of $\mathrm{L}$-amino acid RNA complexes $\left(\Sigma R_{i} L\right)$ to D-amino acid RNA complexes $\left(\Sigma R_{i} D\right)$ is given by the lower expression, taking all equilibria and their competition into account. $R_{i}$ are the total concentrations of each RNA in the population; for example, as defined here by selection (e.g., Tables 1, 3). As His concentration increases, more RNAs participate but the population ratio $\Sigma R_{i} L / \Sigma R_{i} D$ embraces complexes formed at lower concentrations, and therefore need not vary rapidly.

Using observed RNA abundances from unbiased selections, 0.86 RNAs like RNA 67, 0.12 RNAs like RNA 23 and 0.02 RNAs like RNA $62 \mathrm{~b}$, with the $K^{\prime}$ 's measured for prototypical RNA examples (Fig. 4; Table 4), L-His bound to all RNAs $\left(\sum R_{i} L\right)$ would be substantially more frequent than D-His $\left(\Sigma R_{i} D\right)$ (Fig. 7). Inclusion of the strong minor D-His

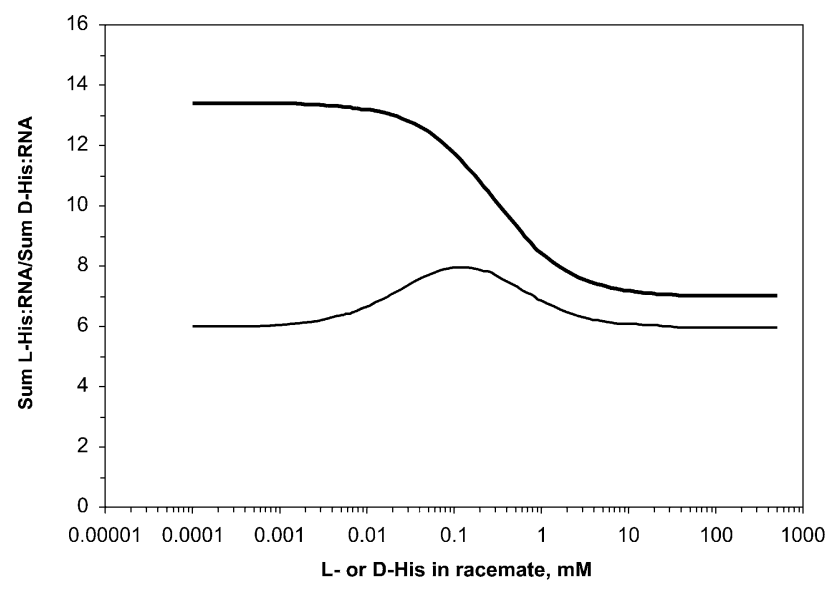

FIGURE 7. Ratio of total L-His bound by RNA $\left(\Sigma R_{i} L\right.$, see text equations) to total $\mathrm{D}$-His bound by RNA $\left(\sum R_{i} D\right)$ versus concentration of racemic L- or D-His for a population like that selected in these experiments. Upper line: A population of RNA 67 and RNA 23-like sites only. Lower line: RNA 67, RNA 23, and RNA 62b-like sites in selected proportions; $86 \%, 12 \%$, and $2 \%$, respectively. 
site (as in RNA 62b and RNA 114) in the selected population is uncertain because these appeared only in one population where they were favored by flanking tags (Fig. 4), within a 21-nt selection that was noticeably anomalous statistically (above). Therefore the L-His:RNA/D:His RNA ratio is shown twice, without (Fig. 7, upper line) and with (Fig. 7, lower line) the minor D-His site at its observed overall abundance. Minor D-His site frequency is likely overestimated because of tag effects, so true selected population behavior lies between the upper and lower lines of Figure 7.

The estimated ratio of amino acid-RNA complexes, $\Sigma R_{i} L /$ $\Sigma R_{i} D$, varies only about twofold over more than six orders of magnitude in racemic His concentration, up to hundreds millimolar. We conservatively approximate this result by saying the ratio is greater than or equal to sevenfold, the median of the lower curve. This conclusion also is independent of RNA concentration as long as His is in excess of RNA. Thus, a robust implication of all selection data taken together (Fig. 7) is that greater than or equal to seven of eight His:RNA complexes would contain L-His. Accordingly, these data support the idea that a more probable D-ribose RNA:L-amino acid complex may have made selection of L-His for translation likely.

\section{Early D-ribose dominance}

Such results reduce preference for L-histidine to a simpler question: How might D-ribose RNAs have become dominant (for review, see Sandars 2005), and subsequently selected L-amino acids? Constrained, but chemically possible mechanisms exist (Sandars 2005) by which chirality fluctuations might have been amplified to yield early homochirality favoring D-ribose RNAs. Homochiral D-ribose RNAs might become prevalent early (before translation), for example, to avoid enantiomeric cross inhibition of their own replication (Joyce et al. 1984).

\section{The mirror world: L-ribose RNA and D-His}

Because one can envision watching these same interactions in a mirror, we posit a symmetrical conclusion for the mirror world. The same electromagnetic forces act in a mirror world that contains L-ribose RNA and D-His; thus we also conclude that the simplest L-ribose-RNA prefers D-His, and by the same factor. This conclusion requires that no intrinsically chiral forces (like the electroweak force) link RNA and amino acids, though such interactions have been occasionally suggested (Mason 1987; MacDermott 1995). However, the complementarity of opposite stereoisomers has been thoroughly tested by synthesis of both D- and L-ribose RNA aptamers (spiegelmers). An RNA-arginine interaction (Nolte et al. 1996), as well as an RNA-adenosine interaction (Klussmann et al. 1996), quantitatively invert their stereospecificity, suggesting that intrinsically chiral forces between RNA and small biomolecules are undetectable, as expected for normal electro- magnetic interactions. This is true also of the major RNA L-His binding site, reisolated here, which inverts its chiral preference when made of L-ribose RNA (Ruta et al. 2006). Accordingly, if L-ribose life exists, it may well utilize D-histidine.

Finally, other amino acids should be examined. Chiral D-ribose in RNA may be more, or less, influential in RNA binding sites directed at other amino acids. Thus, the code could conceivably have been initiated by amino acid interactions that were even more, or even less, highly specific than those we have measured.

\section{MATERIALS AND METHODS}

\section{Preparation of selection matrix}

L-histidine and D-histidine were coupled to Long Chain Alkylamino Controlled-Pore Glass (CPG) beads (Millipore; $125-177 \mu \mathrm{m}$ ) as a mixture and also individually as described before (Illangasekare and Yarus 2002), except CPG beads were used instead of Sepharose. Glass beads, because they are a frozen liquid, are unlikely to have a chiral substructure.

Measured rates of attachment of L-His and D-His to CPG beads (from the absorbance of the released activating group) were equal. The concentration of L-His and D-His on CPG beads was $\sim 1.5$ $\mathrm{mM}$, thus the L-His and D-His concentrations were $\sim 0.75 \mathrm{mM}$ each in the mixed bed used for selection. The same preparation of racemic His-CPG was used for all selections. In columns containing only one enantiomer, concentrations were $1.5 \mathrm{mM} \mathrm{L}-\mathrm{His}$ or D-His. CPG column beds of $0.4 \mathrm{~mL}$ were used in the selection. Pure L-His-CPG and D-His-CPG beads were used to analyze the affinity of individual RNA to L-histidine and D-histidine. Counterselection columns contained CPG beads reacted with a 50-fold excess of acetic anhydride over amino groups.

\section{Selection procedure}

Six different random DNA libraries $\left(3 \times 10^{14}\right.$ DNA individual sequences or $600 \mathrm{pmol}$ ) with varying numbers $(\mathrm{N})$ of contiguous randomized nucleotides, $15 \mathrm{~N}, 18 \mathrm{~N}, 21 \mathrm{~N}, 27 \mathrm{~N}, 35 \mathrm{~N}$, and $45 \mathrm{~N}$, were prepared individually by PCR amplification of the following DNA template (IDT):

\section{taatacgactcactataGGACAAGCTAGCTGACAGGWX(N)YZAACC TGACAGTTGGCAGAAGG}

Nucleotides WX YZ were different for every random length, as shown in Figure 2. Underlined nucleotides indicate the $\mathrm{T}_{7}$ promoter. Half of the amplified PCR library was transcribed with T7 RNA polymerase. Starting RNA pool contained 3 nmols of RNA from each random length.

Cycles of selection at $24^{\circ} \mathrm{C}$ used a $0.4 \mathrm{~mL}$ column of L\&D HisCPG. The selection buffer contained $350 \mathrm{mM} \mathrm{NaCl}, 350 \mathrm{mM} \mathrm{KCl}$, $5 \mathrm{mM} \mathrm{MgCl}_{2}, 5 \mathrm{mM} \mathrm{CaCl}_{2}$, and $50 \mathrm{mM}$ HEPES, pH 7. This elevated ionic strength was required to reduce nonspecific adsorption of RNA on the glass beads. Renatured RNA (1-2 nmols) (Illangasekare and Yarus 2002) was applied to the L\&D His-CPG column pre-equilibrated with selection buffer and washed with four to seven column volumes of the same buffer (wash volume increased as the selection progressed). Elution used $2 \mathrm{~mL}$ of $3 \mathrm{mM}$ 
L-His and $3 \mathrm{mM} \mathrm{D}$-His in addition to buffer components. Eluted RNA was reverse transcribed and the DNA was amplified and transcribed into RNA (Ciesiolka et al. 1996) for the following cycle. In every cycle except cycle 1 , selection was preceded by counterselection on an acetylated CPG column to remove RNA with affinity for acetylated CPG. Eluted RNA from cycle 6 was cloned (Novagen PT7 Blue-3 Blunt cloning kit) and the individual clones were sequenced.

\section{Doped reselection}

The following DNA templates were used in the doped selection. The nucleotides in italics (35) were doped to $30 \% ; 10 \%$ of each mutant nucleotide (Fig. 4):

Major L-His RNA 67 doped sequence: taatacgactcactataGGAAAGGACAAGCTAGCACACAGGAGAGA GGGTGTAATGGTAGGAACGACCTGAGTGTTGGCAGGTC GGAGAG;

Major D-His RNA 23 doped sequence:

taatacgactcactataGGAAAGGACAAGCTAGCACACAGGAGGGG ATCGAAAATGTAACCATCGACCTGAGTGTTGGCAGGTCG GAGAG; and

Minor D-His RNA 62b doped sequence: taatacgactcactataGGAAAGGACAAGCTAGCACACAGGAGATTT AATTGGGGGTGGTCTGAGACCTGAGTG TTGGCAGGTCG GAGAG.

DNA ( $1.2 \mathrm{nmol}\left[7 \times 10^{14}\right.$ molecules $\left.]\right)$ was used for transcription of the initial doped RNA pool. Four nanomoles of doped RNA was applied to the L\&D His-CPG column in the initial cycle and the same procedure as before was followed except that in every cycle RNA was eluted after five column volumes of selection buffer. Eluted RNA from cycle 4 was cloned.

\section{$K_{\mathrm{D}}$ determination}

Dissociation constants for ligands were determined by isocratic affinity chromatography, an equilibrium binding method that exploits the fact that the free RNA fraction is measurable because it moves with eluant, while column-bound RNA is immobile. For isocratic elution from an affinity matrix with and without the free ligand, $K_{\mathrm{D}}$ for free ligand is given by $L\left(V_{\mathrm{el}}-V_{\mathrm{n}}\right) /\left(V_{\mathrm{e}}-V_{\mathrm{el}}\right)$ (Illangasekare and Yarus 2002), where $L$ is the concentration of free solution ligand, $V_{\mathrm{el}}$ and $V_{\mathrm{e}}$ are the median elution volumes of the RNA in the presence and absence of the ligand in the buffer and $V_{\mathrm{n}}$ is the median elution volume in the absence of any affinity (approximated by random RNA). Thus, plots of $\left(V_{\mathrm{e}}-V_{\mathrm{el}}\right) /\left(V_{\mathrm{el}}-\right.$ $V_{\mathrm{n}}$ ) versus free ligand concentration should be linear with a slope of $\left(K_{\mathrm{D}}\right)^{-1}$. As plots in Figure 6 show, RNA obeys this relation very accurately during His affinity chromatography, showing that equilibrium behavior is maintained during chromatography over a range of histidine concentrations. The use of $V_{\mathrm{e}}$ from an experiment in the absence of the small molecule corrects for some unknown properties of the column, such as accessibility of immobilized ligand. Observed variance of the slope of the plots (quoted as \pm SEM in the text) was propagated to the calculated $K_{\mathrm{D}}$ by conventional means. Buffer used in these measurements was the same as the selection buffer. D-His CPG was used to measure the $K_{\mathrm{D}}$ values for RNA 23 and RNA 62b, and L-His CPG was used for RNA 67.

\section{SUPPLEMENTAL MATERIAL}

Supplemental material can be found at http://www.rnajournal.org.

\section{ACKNOWLEDGMENTS}

We thank Irene Majerfeld for comments on a draft manuscript, and the NIH (GM 48080, along with its bioinformatics supplement GM48080-13S1) as well as the CU NASA Astrobiology Center NCC2-1052 for support. We particularly thank Dr. Patrick Sandars of the Oxford Physics Department, who originally persuaded us to undertake this problem.

Received July 22, 2010; accepted August 27, 2010.

\section{REFERENCES}

Anderson PC, Mecozzi S. 2005a. Identification of a 14mer RNA that recognizes and binds flavin mononucleotide with high affinity. Nucleic Acids Res 33: 6992-6999.

Anderson PC, Mecozzi S. 2005b. Unusually short RNA sequences: design of a 13-mer RNA that selectively binds and recognizes theophylline. J Am Chem Soc 127: 5290-5291.

Batey RT, Gilbert SD, Montange RK. 2004. Structure of a natural guanine-responsive riboswitch complexed with the metabolite hypoxanthine. Nature 432: 411-415.

Brown L, Cai T, DasGupta A. 2001. Interval estimation for a binomial proportion. Stat Sci 16: 101-117.

Carothers JM, Oestreich SC, Davis JH, Szostak JW. 2004. Informational complexity and functional activity of RNA structures. J Am Chem Soc 126: 5130-5137.

Ciesiolka J, Illangasekare M, Majerfeld I, Nickles T, Welch M, Yarus M, Zinnen S. 1996. Affinity selection-amplification from randomized ribooligonucleotide pools. Methods Enzymol 267: 315-335.

Coleman TM, Huang F. 2002. RNA-catalyzed thioester synthesis. Chem Biol 9: 1227-1236.

Coleman TM, Huang FH. 2005. Optimal random libraries for the isolation of catalytic RNA. RNA Biol 2: 129-136.

Devore JL. 2008. Probability and statistics for engineering and the sciences. Thomson Brooks/Cole, Belmont, CA.

Freeland SJ, Knight RD, Landweber LF. 1999. Do proteins predate DNA? Science 286: 690-692.

Illangasekare M, Yarus M. 2002. Phenylalanine-binding RNAs and genetic code evolution. J Mol Evol 54: 298-311.

Janas T, Widmann JJ, Knight R, Yarus M. 2010. Simple, recurring RNA binding sites for L-arginine. RNA 16: 805-816.

Johnson DB, Wang L. 2010. Imprints of the genetic code in the ribosome. Proc Natl Acad Sci 107: 8298-8303.

Joyce GF, Visser GM, van Boeckel CA, van Boom JH, Orgel LE, van Westrenen J. 1984. Chiral selection in poly(C)-directed synthesis of oligo(G). Nature 310: 602-604.

Klussmann S, Nolte A, Bald R, Erdmann VA, Furste JP. 1996. Mirrorimage RNA that binds D-adenosine. Nat Biotechnol 14: 11121115.

Knight R, De Sterck H, Markel R, Smit S, Oshmyansky A, Yarus M. 2005. Abundance of correctly folded RNA motifs in sequence space, calculated on computational grids. Nucleic Acids Res 33: 5924-5935.

Legiewicz M, Yarus M. 2005. A more complex isoleucine aptamer with a cognate triplet. J Biol Chem 280: 19815-19822.

Legiewicz M, Lozupone C, Knight R, Yarus M. 2005. Size, constant sequences, and optimal selection. RNA 11: 1701-1709.

Lehman N. 2004. Assessing the likelihood of recurrence during RNA evolution in vitro. Artificial Life 10: 1-22.

Lozupone C, Changayil S, Majerfeld I, Yarus M. 2003. Selection of the simplest RNA that binds isoleucine. RNA 9: 1315-1322. 
MacDermott AJ. 1995. Electroweak enantioselection and the origin of life. Orig Life Evol Biosph 25: 191-199.

Majerfeld I, Yarus M. 2005. A diminutive and specific RNA binding site for L-tryptophan. Nucleic Acids Res 33: 5482-5493.

Majerfeld I, Puthenvedu D, Yarus M. 2005. RNA affinity for molecular L-histidine; genetic code origins. J Mol Evol 61: 226-235.

Mason SF. 1987. Universal dissymmetry and the origin of biomolecular chirality. Biosystems 20: 27-35.

Nolte A, Klussmann S, Bald R, Erdmann VA, Furste JP. 1996. Mirrordesign of L-oligonucleotide ligands binding to L-arginine. Nat Biotechnol 14: 1116-1119.

Paul N, Springsteen G, Joyce GF. 2006. Conversion of a ribozyme to a deoxyribozyme through in vitro evolution. Chem Biol 13: 329-338.

Peterson GC. 2010. "Fairness Analysis via Poissonization." PhD thesis, University of Colorado, Boulder.

Profy AT, Usher DA. 1984. Stereoselective aminoacylation of polyribonucleotides. J Am Chem Soc 106: 5030-5031.

Ruta J, Ravelet C, Grosset C, Fize J, Ravel A, Villet A, Peyrin E. 2006. Enantiomeric separation using an 1-RNA aptamer as chiral additive in partial-filling capillary electrophoresis. Anal Chem 78: 3032-3039.

Sandars PGH. 2005. Chirality in the RNA world and beyond. Int J Astrobiol 4: 49-61.

Schneider TD, Stormo GD, Gold L, Ehrenfeucht A. 1986. Information content of binding sites on nucleotide sequences. J Mol Biol 188: $415-431$.
Tamura K, Schimmel P. 2004. Chiral-selective aminoacylation of an RNA minihelix. Science 305: 1253. doi: 10.1126/science.1099141.

Tamura K, Schimmel PR. 2006. Chiral-selective aminoacylation of an RNA minihelix: Mechanistic features and chiral suppression. Proc Natl Acad Sci 103: 13750-13752.

Vlassov A, Khvorova A, Yarus M. 2001. Binding and disruption of phospholipid bilayers by supramolecular RNA complexes. Proc Natl Acad Sci 98: 7706-7711.

Wickramasinghe NS, Lacey JC Jr. 1992. Esterification of all four monoribonucleotides with acetyl-D-L-valine proceeds with a preference for the $\mathrm{D}$-isomer but the $\mathrm{D} / \mathrm{L}$ ratio in the products declines as a function of the hydrophobicity of the nucleotide. Bioorg Chem 20: 265-268.

Yarus M. 2001. On translation by RNAs alone. Cold Spring Harb Symp Quant Biol 66: 207-215.

Yarus M, Knight RD. 2004. The scope of selection. In The genetic code and the origin of life (ed. LR Pouplana), pp 75-91. Landes Bioscience, Georgetown, TX.

Yarus M, Welch M. 2000. Peptidyl transferase: ancient and exiguous. Chem Biol 7: R187-R190.

Yarus M, Caporaso JG, Knight R. 2005. Origins of the genetic code: the escaped triplet theory. Annu Rev Biochem 74: 179-198.

Yarus M, Widmann JJ, Knight R. 2009. RNA-amino acid binding: A stereochemical era for the Genetic Code. J Mol Evol 69: 406429. 

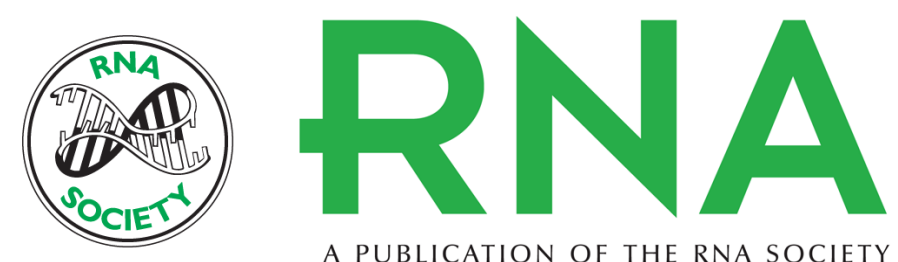

A PUBLICATION OF THE RNA SOCIETY

\section{Chiral histidine selection by D-ribose RNA}

Mali Illangasekare, Rebecca Turk, G. Colin Peterson, et al.

RNA 2010 16: 2370-2383 originally published online October 12, 2010

Access the most recent version at doi:10.1261/rna.2385310

Supplemental
Material http://rnajournal.cshlp.org/content/suppl/2010/10/12/rna.2385310.DC1

References This article cites 37 articles, 10 of which can be accessed free at:

http://rnajournal.cshlp.org/content/16/12/2370.full.html\#ref-list-1

License

Email Alerting Receive free email alerts when new articles cite this article - sign up in the box at the Service top right corner of the article or click here.

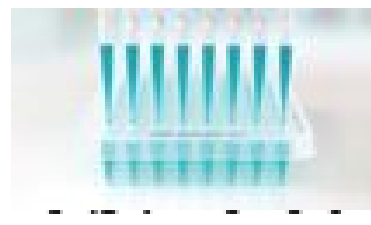

Providing Precise Solutions for your research.

To subscribe to RNA go to:

http://rnajournal.cshlp.org/subscriptions 